\title{
Rational dosing of gabapentin and pregabalin in chronic kidney disease
}

This article was published in the following Dove Press journal:

Journal of Pain Research

27 January 2017

Number of times this article has been viewed

\author{
Mena Raouf' \\ Timothy J Atkinson' \\ Meredith W Crumb' \\ Jeffrey Fudin ${ }^{2-5}$ \\ 'VA Tennessee Valley Healthcare \\ System, Murfreesboro, Nashville, \\ TN, ${ }^{2}$ Stratton VA Medical Center, \\ ${ }^{3}$ Albany College of Pharmacy and \\ Health Sciences, Albany, NY, ${ }^{4}$ Western \\ New England University College of \\ Pharmacy, Springfield, MA, ${ }^{5}$ Scientific \\ and Clinical Affairs, Remitigate LLC, \\ Delmar, NY, USA
}

\section{Introduction}

Renal dose adjustments for gabapentin and pregabalin are ubiquitously evident in the medical literature. All manufacturers for these branded and generic dosage forms list dosing recommendations relative to creatinine clearance $(\mathrm{CrCl})$ for both medications (Table 1). ${ }^{1,2}$ However, the basis of these recommendations has not been well articulated.

\section{Pharmacology}

Gabapentin and pregabalin are commonly used first-line agents for diabetic peripheral neuropathy and other common neuropathies. Pharmacologically, both agents inhibit alpha-2-delta $(\alpha 2 \delta)$ subunit of N-type voltage-gated calcium channels, a key receptor involved in regulating the excitability of neurons. ${ }^{3}$ Peripheral nerve injury results in the upregulation of $\alpha 2 \delta$-1 receptors in the dorsal root ganglion neurons and subsequent increase in the trafficking of $\alpha 2 \delta-1$ to nerve terminals within the spinal cord. ${ }^{3-5}$ Inhibition of $\alpha 2 \delta$ - 1 receptors decreases calcium-mediated release of excitatory neurotransmitters into the dorsal horn and subsequently reduces pain signaling. ${ }^{4-6}$ Despite sharing the same mechanism of action, there are key pharmacologic differences between both agents. Pregabalin has six times higher binding affinity for the $\alpha 2 \delta$-1 receptor compared to gabapentin. ${ }^{7}$ Gabapentin follows zero-order saturable absorption, where its bioavailability decreases as the dose increases. ${ }^{1,7}$ Following oral administration, gabapentin's bioavailability is $60 \%, 47 \%, 34 \%$, and $33 \%$, with $900,1200,2400$, and $3600 \mathrm{mg}$ /day in three divided doses, respectively. ${ }^{1}$ Notwithstanding, the two extended-release branded products, Horizant (gabapentin enacarbil) and Gralise (a prodrug), are pharmaceutically designed to enhance absorption. ${ }^{89}$ Pregabalin exhibits linear absorption with bioavailability equal to or greater than $90 \%$ irrespective of the dose, which gives it a more predictable pharmacokinetic profile. ${ }^{2,7}$

\section{Pharmacokinetics and renal handling}

Challenges to achieving therapeutic concentrations necessary to achieve efficacy require consideration of the pharmacokinetic properties of both gabapentin and pregabalin. Both medications do not undergo hepatic metabolism and are primarily excreted unchanged in the urine. ${ }^{7}$ A pharmacokinetic advantage is the absence of hepatic cytochrome P450-related drug-drug and drug-food interactions. In pharmacokinetic
Correspondence: Timothy J Atkinson VA Tennessee Valley Healthcare System, 3400 Lebanon Pike, Murfreesboro, TN 37I29, USA

Email timothy.atkinson @va.gov 
Table I Recommended dose adjustments based on varying degrees of renal impairment

\begin{tabular}{lll}
\hline CrCl cutoff & \multicolumn{2}{l}{ Maximum recommended dosing } \\
\cline { 2 - 3 } & Gabapentin' & Pregabalin $^{2}$ \\
\hline $30-59 \mathrm{~mL} / \mathrm{min}$ & $700 \mathrm{mg}$ BID & $150 \mathrm{mg}$ BID \\
& & $100 \mathrm{mg}$ TID \\
$15-29 \mathrm{~mL} / \mathrm{min}$ & $700 \mathrm{mg}$ once a day & $75 \mathrm{mg}$ BID \\
& & $50 \mathrm{mg}$ TID \\
$<15 \mathrm{~mL} / \mathrm{min}$ & $300 \mathrm{mg}$ once a day & $75 \mathrm{mg}$ once a day \\
Supplemental doses & $100-300 \mathrm{mg}$ & $75-150 \mathrm{mg}$ post \\
in hemodialysis & post dialysis & dialysis \\
\hline
\end{tabular}

Abbreviation: $\mathrm{CrCl}$, creatinine clearance.

studies, clearance of both medications was linearly correlated with $\mathrm{CrCl}$. Gabapentin's apparent total clearance is $100 \mathrm{~mL} /$ min in adults with normal renal function, which is essentially equivalent to $\mathrm{CrCl}$ and does not suggest the involvement of tubular reabsorption. ${ }^{1}$ Some evidence suggest that active tubular secretion mediated by organic cation transporter-1 (OCT-1) may play a role in gabapentin's renal clearance. Individuals with genetic variation in OCT-1 may have altered renal clearance; however, the clinical significance has yet to be elucidated and may be negligible as gabapentin is primarily excreted unchanged via filtration. ${ }^{10}$

Pregabalin's apparent total clearance is $67-81 \mathrm{~mL} / \mathrm{min}$ in young healthy subjects and is therefore thought to undergo tubular reabsorption to some extent. ${ }^{2}$ Hemodialysis (HD) removes approximately $35 \%$ of gabapentin and $50 \%-60 \%$ of pregabalin, where supplemental doses are generally recommended post-HD. ${ }^{1,2}$

\section{Therapeutic dosing targets}

Therapeutic dosing targets of both medications have been established in clinical trials for neuropathic pain (gabapentin $1800-3600 \mathrm{mg} /$ day; pregabalin $150-600 \mathrm{mg}$ /day). However, patients with renal impairment were often excluded from these studies. ${ }^{11-17}$ The aforementioned renal dose adjustments were mainly based on pharmacokinetic studies, some of which were conducted in healthy individuals. To date, no study has evaluated the impact of recommended dosing strategies on clinical efficacy in the management of neuropathic pain for patients with renal dysfunction.

\section{Dosing considerations in chronic kidney disease (CKD)}

CKD alters renal drug elimination by affecting glomerular blood flow, filtration rate, tubular secretion and reabsorption, and renal bioactivation and metabolism. ${ }^{18}$ Additionally, pharmacokinetic handling of medications (absorption, distribution, metabolism, and elimination) may be affected. ${ }^{19}$ Reducing the dose is recommended for medications with narrow therapeutic index. ${ }^{20}$ Extending the interval is recommended for medications with prolonged half-life in renal impairment; however, this may be subtherapeutic and may cause end-of-dose failure. Understanding the pharmacokinetic and pharmacodynamic profiles of medications is important when making these adjustments. Nevertheless, while dosing gabapentinoids, we must also consider reports by the patient that include side effect profile and tolerability as measured against efficacy, irrespective of the theoretical calculations.

\section{A theoretical approach: the Rowland and Tozer equation}

A widely accepted approach to individualize drug dosing in CKD patients based on $\mathrm{CrCl}$ is the Rowland-Tozer method. ${ }^{21}$

Figure 1 correlates with the manufacturer's recommendation for pregabalin to follow a $50 \%$ dose reduction in patients with $\mathrm{CrCl}$ below $60 \mathrm{~mL} / \mathrm{min}$ and greater than $30 \mathrm{~mL} / \mathrm{min}$. For medications with concentration-dependent efficacy, extending the interval while maintaining the same dose is appropriate. For medications with area under the curve (AUC)-dependent efficacy, extending the interval or reducing the dose is appropriate while maintaining the same AUC. The efficacy of pregabalin and gabapentin for neuropathic pain with respect to blood concentration or AUC remains unclear. Notwithstanding, most reports of toxicities were associated with concentrations higher than $15 \mathrm{mg} / \mathrm{L}$ for gabapentin and concentrations higher than $13 \mathrm{mg} / \mathrm{L}$ for pregabalin, whereas individuals with

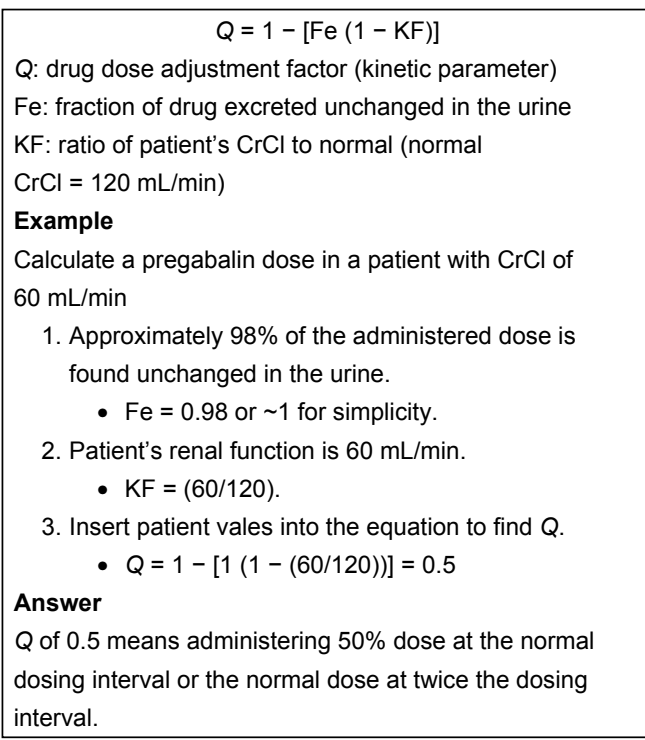

Figure I Rowland-Tozer method. 
normal renal function on maximum recommended dosing yielded concentrations of $\sim 5-8 \mathrm{mg} / \mathrm{L}$ for gabapentin and $2.8-8.2 \mathrm{mg} / \mathrm{L}$ for pregabalin. ${ }^{22-25}$ The elimination half-lives of gabapentin and pregabalin are prolonged with renal impairment leading up to accumulation with repeated dosing. The half-life of gabapentin immediate-release formulation is 5-7 hours in patients with normal renal function and is prolonged up to 52 hours in patients with $\mathrm{CrCl}<30 \mathrm{~mL} / \mathrm{min} .{ }^{26}$ The half-life of pregabalin is 16.7 hours in patients with $\mathrm{CrCl} 30-59 \mathrm{~mL} / \mathrm{min}, 25$ hours in patients with $\mathrm{CrCl} 15-29 \mathrm{~mL} / \mathrm{min}$, and 48.7 hours in patients with $\mathrm{CrCl}<15 \mathrm{~mL} / \mathrm{min} .{ }^{27}$ Therefore, finding the right pharmacokinetic balance is key to promote safety and efficacy, yet this balance remains unknown.

\section{Conclusion}

Gabapentin and pregabalin are commonly used for neuropathic pain in CKD patients but are not fully understood as this population remains excluded from efficacy and safety trials. Renal adjustments for the gabapentinoids are prodigiously recommended in the literature. However, current guidance is based on pharmacokinetic and toxicity studies, but studies confirming efficacy of these dosing strategies are lacking. Considering their widespread use for numerous neuropathic pain conditions, studies evaluating their efficacy at recommended doses in renal impairment should be a priority for future research.

\section{Disclosure}

JF reports the following: Daiichi Sankyo (advisory board); DepoMed (advisory board, speakers bureau); Endo (consultant, speakers bureau); Kaléo (speakers bureau, advisory board); Kashiv Pharma (advisory board); KemPharm (consultant); Pernix Therapeutics (speaker); Remitigate, LLC (owner); and Scilex Pharmaceuticals (consultant). The other authors report no conflicts of interest in this work. This editorial represents the opinions of the authors and has not been reviewed or prepared as part of any government agency or companies listed.

\section{References}

1. Neurontin ${ }^{\circledR}$ (gabapentin) [package insert]. New York, NY: Parke Davis; 2015.

2. Lyrica ${ }^{\circledR}$ (pregabalin) [package insert]. New York, NY: Pfizer; 2016.

3. Bauer CS, Tran-Van-Minh A, Kadurin I, Dolphin AC. A new look at calcium channel $\alpha 2 \delta$ subunits. Curr Opin Neurobiol. 2010;20(5): 563-571.

4. Bauer CS, Rahman W, Tran-van-Minh A, Lujan R, Dickenson AH, Dolphin AC. The anti-allodynic alpha(2)delta ligand pregabalin inhibits the trafficking of the calcium channel alpha(2)delta-1 subunit to presynaptic terminals in vivo. Biochem Soc Trans. 2010;38(2):525-528.
5. Hendrich J, Tran Van Minh A, Heblich F, et al. Pharmacological disruption of calcium channel trafficking by the alpha2delta ligand gabapentin. Proc Natl Acad Sci U S A. 2008;105(9):3628-3633.

6. Heblich F, Tran Van Minh A, Hendrich J, Watschinger K, Dolphin AC. Time course and specificity of the pharmacological disruption of the trafficking of voltage-gated calcium channels by gabapentin. Channels (Austin). 2008;2(1):4-9.

7. Bockbrader HN, Wesche D, Miller RA, Chapel S, Janiczek N, Burger P. A comparison of the pharmacokinetics and pharmacodynamics of pregabalin and gabapentin. Clin Pharmacokinet. 2010;49(10):661-669.

8. Horizant ${ }^{\circledR}$ (gabapentin enacarbil extended-release) [package insert] Santa Clara, CA: Xenoport Inc; 2013.

9. Gralise ${ }^{\circledR}$ (gabapentin) [package insert]. Newark, CA: Depomed; 2012.

10. Urban TJ, Brown C, Castro RA, et al. Effects of genetic variation in the novel organic cation transporter, OCTN1, on the renal clearance of gabapentin. Clin Pharmacol Ther. 2008;83(3):416-421.

11. Backonja M, Beydoun A, Edwards KR, et al. Gabapentin for the symptomatic treatment of painful neuropathy in patients with diabetes mellitus: a randomized controlled trial. JAMA. 1998;280(21):1831-1836.

12. Serpell MG; Neuropathic pain study group. Gabapentin in neuropathic pain syndromes: a randomised, double-blind, placebo-controlled trial. Pain. 2002;99(3):557-566.

13. Rosenstock J, Tuchman M, La Moreaux L, Sharma U. Pregabalin for the treatment of painful diabetic peripheral neuropathy: a double-blind, placebo-controlled trial. Pain. 2004;110(3):628-638.

14. Lesser H, Sharma U, La Moreaux L, Poole RM. Pregabalin relieves symptoms of painful diabetic neuropathy: a randomized controlled trial. Neurology. 2004;63(11):2104-2110.

15. Tolle T, Freynhagen R, Versavel M, Trostmann U, Young JP Jr. Pregabalin for relief of neuropathic pain associated with diabetic neuropathy: a randomized, double-blind study. Eur J Pain. 2008;12(2):203-213.

16. Sabatowski R, Gálvez R, Cherry DA, et al; 1008-045 Study Group. Pregabalin reduces pain and improves sleep and mood disturbances in patients with post-herpetic neuralgia: results of a randomised, placebocontrolled clinical trial. Pain. 2004;109(1-2):26-35.

17. Freynhagen R, Strojek K, Griesing T, Whalen E, Balkenohl M. Efficacy of pregabalin in neuropathic pain evaluated in a 12-week, randomised, double-blind, multicentre, placebo-controlled trial of flexible- and fixed-dose regimens. Pain. 2005;115(3):254-263.

18. Aymanns C, Keller F, Maus S, Hartmann B, Czock D. Review on pharmacokinetics and pharmacodynamics and the aging kidney. Clin J Am Soc Nephrol. 2010;5(2):314-327.

19. Pichette V, Leblond FA. Drug metabolism in chronic renal failure. Curr Drug Metab. 2003;4(2):91-103.

20. Matzke GR, Aronoff GR, Atkinson AJ Jr, et al. Drug dosing consideration in patients with acute and chronic kidney disease - a clinical update from Kidney Disease: Improving Global Outcomes (KDIGO). Kidney Int. 2011;80(11):1122-1137.

21. Rowland M, Tozer TN. Clinical Pharmacokinetics: Concepts and Applications. 3rd ed. Philadelphia, PA: Lea \& Febiger; 1995.

22. Zand L, McKian KP, Qian Q. Gabapentin toxicity in patients with chronic kidney disease: a preventable cause of morbidity. Am J Med. 2010; 123(4):367-373.

23. Yoo L, Matalon D, Hoffman RS, Goldfarb DS. Treatment of pregabalin toxicity by haemodialysis in a patient with kidney failure. Am J Kidney Dis. 2009;54(6):1127-1130.

24. Berry DJ, Beran RG, Plunkeft MJ, Clarke LA, Hung WT. The absorption of gabapentin following high dose escalation. Seizure. 2003;12(1):28-36.

25. Berry D, Millington C. Analysis of pregabalin at therapeutic concentrations in human plasma/serum by reversed-phase HPLC. Ther Drug Monit. 2005;27(4):451-456.

26. Blum RA, Comstock TJ, Sica DA, et al. Pharmacokinetics of gabapentin in subjects with various degrees of renal function. Clin Pharmacol Ther. 1994;56(2):154-159.

27. RandinitisEJ, PosvarEL, Alvey CW, SedmanAJ, Cook JA, Bockbrader HN. Pharmacokinetics of pregabalin in subjects with various degrees of renal function. J Clin Pharmacol. 2003;43(3):277-283. 
Dove Medical Press encourages responsible, free and frank academic debate. The content of the Journal of Pain Research 'Editorial' section does not necessarily represent the views of Dove Medical Press, its officers, agents, employees, related entities or the Journal of Pain Research editors. While all reasonable steps have been taken to confirm the content of each Editorial, Dove Medical Press accepts no liability in respect of the content of any Editorial, nor is it responsible for the content and accuracy of any Editorial.

Journal of Pain Research

Publish your work in this journal

The Journal of Pain Research is an international, peer reviewed, open access, online journal that welcomes laboratory and clinical findings in the fields of pain research and the prevention and management of pain. Original research, reviews, symposium reports, hypothesis formation and commentaries are all considered for publication.

The manuscript management system is completely online and includes a very quick and fair peer-review system, which is all easy to use. Visit http://www.dovepress.com/testimonials.php to read real quotes from published authors. 